\title{
\#26
}

\section{LENGUA, EXILIO E IDENTIDAD EN DOS ESCRITORAS FRANCÓFONAS: KIM THÚY Y LAURA ALCOBA}

Ángeles Sánchez Hernández

Universidad de Las Palmas de Gran Canaria

Artículo || Recibido: 25/07/2021 | Aceptado: 29/11/2021 | Publicado: 01/2022 DOI 10.1344/452f.2022.26.3 angeles.sanchez@ulpgc.es

Ilustración || @ Andrés Müller - Todos los derechos reservados

Texto || @ Ángeles Sánchez Hernández - Licencia: Atribución-NoComercial-SinDerivadas 4.0 Internacional de Creative Commons

\section{(c) (i) $(5)$}



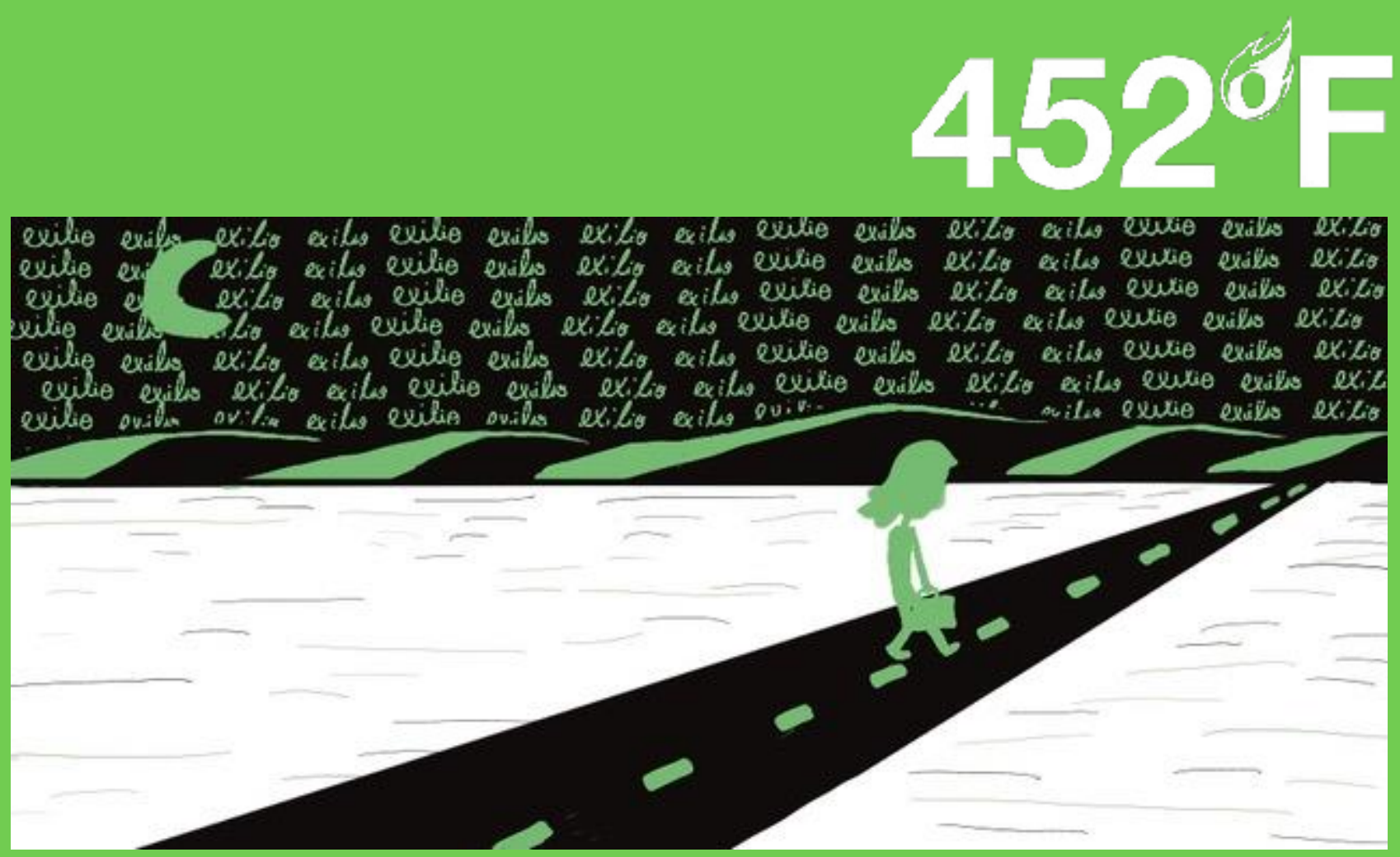

Resumen || El artículo presenta la obra de dos escritoras de lengua francesa, Kim Thúy y Laura Alcoba, que han sufrido el exilio y que habitan en dos países de asilo distintos: Canadá y Francia. Las dos despliegan una narración que articula la ficción y la realidad de forma innovadora para dejar constancia de una experiencia del exilio compartida con otras personas; en buena parte, la toma de la palabra pública con sus novelas trata de dar voz a estas vivencias silenciadas. La problemática de la identidad adquiere una dimensión primordial en cuya construcción el elemento familiar se instaura como fundamento esencial. El ensamblaje de la identidad de ambas escritoras se construye entre el presente y el pasado revisitado desde la edad adulta. En sus novelas, las narradoras de sus historias reivindican la construcción identitaria híbrida o transcultural, rasgo que caracteriza su personalidad literaria. La singularidad que une a Alcoba y Thúy yace en la elección de una lengua otra que la materna, que las dos conocen sobradamente; sin embargo, el francés es elegido para dar testimonio de su recorrido vital. Este estudio trata de constatar el porqué de esa elección que les ha dado la libertad íntima de expresión para contar su exilio y su integración.

\section{Palabras clave || Lengua | Exilio | Identidad | Laura Alcoba | Kim Thúy}

Abstract || This article presents the work of two French-language writers, Kim Thúy and Laura Alcoba, who have been exiled and live in two different countries of asylum: Canada and France. Both deploy a narrative that articulates fiction and reality in innovative ways to record their experience of exile shared with others; to a large extent, their novels' public speaking is an attempt to give voice to these silenced experiences. The assemblage of the identity of both writers is constructed between the present and the past revisited from adulthood. In their novels, the narrators of their stories claim a hybrid or transcultural construction of identity, a trait that constitutes the basis of their personality as writers. The singularity that unites Alcoba and Thúy lies in the choice of a language other than their mother tongue, which they both know well. However, French, which they learned later, is chosen to bear witness to their life's journey. This study attempts to determine the reasons for this choice, which gave them the intimate freedom of expression to tell the story of their exile and their integration at the same time.

\section{Keywords || Language | Exile | Identity | Laura Alcoba | Kim Thúy}

Resum || L'article presenta l'obra de dues escriptores de llengua francesa, Kim Thúy i Laura Alcoba, que han sofert l'exili i que habiten en dos paiisos d'asil diferents: Canadà i França. Les dues despleguen una narració que articula la ficció i la realitat de manera innovadora per a deixar constància d'una experiència de l'exili compartida amb altres persones; en bona part, la presa de la paraula pública amb les seves novel-les tracta de donar veu a aquestes vivències silenciades. La problemàtica de la identitat adquireix una dimensió essencial en la construcció de la qual l'element familiar s'instaura com a fonament essencial. L'assemblatge de la identitat de totes dues escriptores es construeix entre el present i el passat revisitat des de l'edat adulta. En les seues novel-les, les narradores de les seves històries reivindiquen la construcció identitària híbrida o transcultural, aquest tret caracteritza la seva personalitat literària. La singularitat que uneix a Alcoba i Thúy jeu en l'elecció d'una llengua altra que la materna que les dues coneixen àmpliament; no obstant això, el francès és triat per a donar testimoniatge del seu recorregut vital. Aquest estudi tracta de constatar el perquè d'aquesta elecció que els ha donat la llibertat íntima d'expressió per a explicar el seu exili i la seva integració. 


\section{Introducción}

El presente estudio se centra en las obras de Laura Alcoba (La Plata, 1968) y de Kim Thúy (Saigón, 1968), quienes comparten la experiencia del exilio, $y$, desde ese punto de partida, tejen sus tramas literarias. En su infancia, ambas escritoras huyen de sus países respectivos por cuestiones políticas a una edad similar, a los diez años. Sus lugares de origen son diferentes cultural y geográficamente, pero ellas encuentran en la lengua francesa el mejor medio de expresión. La relación con el francés difiere en ellas; este idioma formaba parte de la infancia de Kim Thúy por ser la lengua de cultura en Vietnam en la época colonial, y su familia se había educado en ella; sin embargo, para Laura Alcoba el francés debe ser aprendido en su infancia para poder reunirse con su madre en París. Las dos autoras comparten una plena integración en los países de adopción: Canadá y Francia. Las obras en las que nos basaremos serán por parte de Thúy: $R u$ (2009), Vi (2016); y del lado de L. Alcoba: Manèges (2007), Le bleu des abeilles (2013) y La danse de l'araignée (2017).

La vivencia de la expulsión o la huida del país nativo deja una huella psíquica en el individuo que la soporta; la experiencia del exilio perturba la relación humana con el tiempo, el espacio y la identidad (Pénicaud, 2015). Por tanto, la problemática de la identidad adquiere una dimensión singular en la persona migrante; en esa perspectiva, las narradoras de estas novelas retornan al pasado y van presentando una realidad fragmentada que dialoga con el presente. Cuando E. W. Said habla de sus vivencias, tras la partida de Palestina, afirma que los lugares por los que transcurrió su vida, desde Jerusalén a EE. UU., «poseen una red compleja y densa de valencias que ha constituido una parte muy importante de mi proceso de crecimiento, de mi asunción de identidad y de la formación de mi conciencia de mí mismo y de los demás» (Said, 2001:14). En ese proceso de formación personal, la lengua puede considerarse una patria esencial en la construcción del ser humano al traspasar los límites de fronteras políticas o territoriales, permitiendo que la asunción de identidad, así como la toma de conciencia de mí mismo y de los demás, se realice sin traumas.

Los escritores en situación de exilio realizan con frecuencia una búsqueda ligada al problema de la identidad (Riendeau, 2009: 137), cuya fundamentación reside en un proceso de aculturación en el que intervienen diferentes aspectos relativos a las culturas que entran en contacto y al modelo de integración de los países de asilo (Mata Barreiro, 2004: 41). Existe una cierta confusión entre los términos de aculturación o transculturación; según el diccionario, la aculturación implica incorporar a un individuo elementos de otro grupo cultural y la transculturación comprende la recepción de formas de cultura procedentes de otro grupo que sustituyen de un modo más o menos completo a las propias ${ }^{1}$, creando así una nueva identidad cultural fruto de la hibridación. Compartimos la opinión de Pérez-Brignoli (2017: 102) al afirmar que «en el mundo globalizado que se impone a finales del siglo $X X$, todo es hibridez y mestizaje, de modo que se constata una vez más que no existe la pureza cultural». Las obras de estas dos escritoras muestran las múltiples conexiones entre las experiencias del pasado en el país natal y su relación con la construcción de la identidad de las múltiples narradoras en las que 
van dispersando los datos de sus biografías poniendo de relieve una identidad híbrida.

El éxodo constituye una característica del mundo contemporáneo que obliga al sujeto migrante a entrar en un proceso de interiorización paradójico; por una parte, tiene que abandonar lo que era y, por otra, debe actualizar lo que le constituye en el presente. La escritura se convierte así en «un espace spécifique d'expression et d'articulation de ces états existentiels en nous amenant à la réflexion sur l'expérience de cette existence "hors du monde" des écrivains" (Quang Pham, 2020: 143). Según Alexis Nouss (2015) toda tentativa de pensar la experiencia del exilio exige una reflexión desde una doble perspectiva: la individual y la colectiva. K. Thúy y L. Alcoba, al revisar su pasado, se integran en la historia de aquellos con quienes compartieron la salida del país de origen. El trabajo de memoria que acometen los escritores exiliados es susceptible de hacer comprender mejor la historia de las sociedades surgidas de comunidades «ethnoculturelles» (Mata Barreiro, 2020: 29), lo que refuerza el potencial intercultural de la escritura migrante.

Generalmente, el exilio se vive como una ruptura o, al menos, como una fractura; pero lo que el exiliado llora no es la pérdida de una parcela de tierra, sino que lamenta la perdida de la relación con el ser que ha perdido y que le definía; no se trata de una cuestión de «tener» sino de «ser» (Bianchi, 2005: 1). El individuo en el exilio siente esta privación como un castigo de duración indeterminada y del que le quedan secuelas que le recuerdan con insistencia su condición. Laura Alcoba y Kim Thúy confirman la necesidad de recoger las vivencias que han constituido su identidad presente, pero enraizándolas en su infancia en el país natal para dejar testimonio escrito de la colectividad de exiliados que las experimentaron. La diferencia entre ambas estriba en que Thúy pertenece a un país colonizado durante años por los franceses, elemento que se irá revelando a través de sus obras en distintos aspectos en los que afectó a su familia.

La problemática del exilio está a menudo anclada en la cuestión del olvido, que se articula como un fantasma inconsciente de la traición (Desplechin, 2015: 45). En el caso de Laura Alcoba veremos que esa percepción de traición al pasado, a los acontecimientos vividos, se desvela desde el comienzo de su libro, Manèges. El sentimiento de traición y de exilio interior no necesita de grandes hechos históricos ni del abandono de países, en ocasiones basta con sentirse fuera del lugar que la sociedad había determinado para alguien, como en el caso de la escritora Annie Ernaux (Lillebonne, 1940), quien sitúa sus textos dentro de lo que ella denomina «auto-socio-biographie»; Laura Alcoba afirma sentirse influenciada por su proyecto literario (Menestrina, 2020: 68). El exilio constituye en ocasiones una metáfora del sentimiento de exclusión social, permanecer como un ser marginal en una sociedad o en un territorio, aunque se haya nacido en él. Comprobamos con Annie Ernaux que el sentimiento de marginalidad social hace que el individuo construya su identidad en un espacio intermedio, en «l'entre-deux» en terminología de Fabrice Thumerel (2004). 


\section{Relato de filiación e identidad en la escritura migrante francófona}

Las obras de K. Thúy y de L. Alcoba elaboran sus relatos a través de la historia de cada una de sus familias. Dentro de la literatura francesa, los llamados récits de filiation han proliferado de forma notable desde los años ochenta del siglo pasado hasta la actualidad. Este tipo de narraciones poseen la originalidad de realizar una investigación sobre la ascendencia del personaje frente a la autobiografía o la autoficción, que se fijan más en la evolución cronológica del personaje. Dominique Viart (2009: 96), apoyando su teoría sobre los hallazgos de la reflexión psicoanalítica, justifica la expansión de esta tipología narrativa frente a la autobiografía por la incapacidad del ser humano, y por consecuencia del escritor autobiográfico, para acceder a su propio inconsciente. Por esa razón, considera que los escritores sustituyen la investigación de su interioridad por la de la búsqueda en la anterioridad de su familia, siguiendo así los presupuestos de la teoría analítica que asegura que el sujeto forma su psiquismo en los primeros años de vida. Las dos autoras, desde su madurez, vuelven la mirada hacia la infancia en sus países de origen y reviven esa experiencia a partir del momento crucial en el que debieron abandonar la tierra de sus antepasados para ir recorriendo el camino de construcción entre las dos culturas. Para Viart, este tipo de relatos de filiación está unido a una época más que a una escuela literaria, y responde a la necesidad de la literatura de no ignorar hechos que no son solo personales o familiares, sino que tienen un calado social e histórico.

Existe una exigencia de reivindicación social de dejar testimonio escrito de vivencias difíciles como la experiencia del exilio por parte de los protagonistas de la ficción francesa contemporánea. Alexandre Gefen (2016: 420) confirma que estos personajes son individuos frágiles, olvidados por la Historia, y que pertenecen a comunidades devastadas. La dimensión social de las obras de las escritoras que ocupan este estudio ha sido resaltada por ellas con claridad. Laura Alcoba confirma su intención de acometer un proyecto literario relacionado con la autobiografía, pero ignorando la parte de 'auto' para incluir una dimensión comunitaria: «Je vais évoquer cette folie argentine et toutes ces personnes emportées par la violence [...] je pense bien souvent aux morts, mais aussi parce que je sais qu'il ne faut pas oublier les survivants» (Alcoba, 2007:14). Aunque el objetivo personal final es tratar de olvidar aquellos acontecimientos vividos en su infancia por medio de la elucidación de los hechos.

En una entrevista, Alcoba declara: «no estoy trabajando sobre mi historia personal sino con una historia que tiene que ver, en parte, pero que se conecta a partir de la historia de otros» (Menestrina, 2020: 69). Su forma de contar los acontecimientos recurre a situaciones 0 anécdotas personales, tratando de obviar los momentos más íntimos que manifestaran sentimientos o emociones personales; en esta perspectiva, su obra enlaza con el proyecto de escritura de Annie Ernaux, cuyo exilio es interior, producido por un sentimiento de traición, hacia sus padres y su clase social, a través de su estilo seco y áspero, disecciona la realidad vivida como con un bisturí, plasmando los hechos vividos de la forma más objetiva posible. Alcoba reconoce partir de la memoria personal en sus libros, pero lo hace para alcanzar la colectividad. En una perspectiva similar, Kim Thúy redacta 
sus obras partiendo de su mundo íntimo y familiar, abarcando las vivencias de otros muchos boat-people. Ella misma lo constata al encontrarse con otros vietnamitas exiliados que le dicen: «tu as raconté mon histoire. C'est l'univers dans lequel on a vécu» (Rivières, 2010). La escritora canadiense cree que para ser comprendidos en su diversidad los exiliados deben explicar sus diferencias (Malavoy, 2016).

Muchos de los relatos del exilio francófono revisan la historia personal para tratar de ligar el pasado familiar en el país de origen y las vivencias en la tierra que les da asilo. El debate íntimo sobre la identidad de estos escritores está presente en buena parte de sus novelas en las que resulta fácil identificar al protagonista con la biografía del autor. El debate personal trasciende al ámbito comunitario para analizar la reubicación en la tierra de asilo. El relato de filiación constituye una narrativa que se ajusta al análisis y a la descripción de las experiencias de estos escritores cuya vida se ha visto obligada a compartir dos culturas y, con frecuencia, dos lenguas. Las publicaciones de K. Thúy y L. Alcoba están vinculadas íntimamente con su infancia en el país natal y su adolescencia en el nuevo país de acogida. Sus historias se insertan en procesos históricos que han marcado sus países, tanto Vietnam como Argentina. En el primer caso, la huida de vietnamitas tras la implantación del régimen comunista y, en el segundo caso, la dictadura militar de J. Rafael Videla.

El relato de Alcoba parte de las vivencias de la persecución política como hija de activistas montoneros; no se trata del relato de sus padres en torno al conflicto, sino de la visión de la niña que «da cuenta de una subjetividad distinta a la que se perfila en los discursos que recrean el activismo político de los años setenta como heroico» (Rey de Castro, 2017: 216). Kim Thúy retorna a su huida de Vietnam, aunque precisa, en relación a su situación de exiliada, que no puede utilizar la palabra 'exiliada' porque no fue ella quien tomó la decisión de salir del país y que no tiene la misma unión que sus padres con Vietnam. Sin embargo, afirma que las vivencias de aquel momento y su experiencia de refugiada no desaparecen nunca ${ }^{2}:$ :On n'enlève pas ça de quelqu'un. Comme on dit en bon Québécois 'on peut sortir la fille du lac mais pas le lac de la fille', je dirais la même chose pour cette expérience ». Aunque las personas logren salir del campo de refugiados la experiencia permanece en ellos.

Los textos de estas escritoras toman la palabra pública ante la sociedad a la que alude Déborah Lévy-Bertherat (2017: 20-21):

Les enfances meurtries suivent un cheminement sinon vers l'âge adulte ou même la puberté (la sexualité et la séduction n'y ont pas leur place), du moins vers une affirmation de soi par le verbe. Le mutisme des petites filles, leurs échecs, leurs souffrances, sont autant de sources d'où jaillit, paradoxalement, le souffle d'une parole libérée, investie d'une mission mémorielle et vitale: témoigner pour les disparus.

La afirmación pública por medio de la palabra es necesaria para dar a conocer los silencios de todos aquellos que no pudieron dar a conocer su sufrimiento, silenciando así el fantasma inconsciente de la traición del que habla Desplechin (2015: 45); traición a aquellos que fueron asesinados en 
la llamada «casa de los conejos», con quienes compartió su vida durante meses, o traición a todos los desaparecidos argentinos.

En el último siglo, las migraciones se han producido de forma masiva; de ahí, la necesidad de contar las historias vividas para aportar visibilidad a realidades que la Historia no ha contado. La literatura pone cara a esos desconocidos y logra dar enfoques distintos al discurso histórico. Los relatos de filiación proponen nuevas aproximaciones a la memoria colectiva de los pueblos; sin embargo, estos relatos no tratan de organizar el pasado para dar sentido al presente, sino que solo son útiles a estos escritores «para rehacer el vínculo y comprender cómo se llegó allí (Viart, 2019). En las obras de Laura Alcoba y de Kim Thúy, observamos este relato de la historia reciente de dos exiliadas que no proponen al lector historias exóticas ni tampoco historias de miserabilismo, a pesar de haber pasado por situaciones inhumanas. La construcción de la identidad en ambas novelistas, forjada en el exilio, se basa en la integración de ambas culturas de las que no desean desprenderse porque constituyen un elemento enriquecedor.

En la actualidad, las identidades culturales no son exclusivamente nacionales, sino que existen otros elementos que permiten su identificación. Esto hace que, en el mundo globalizado en el que habitamos, gran parte de la población viva de alguna forma una experiencia de mestizaje, como nos confirma Todorov (1996: 23): «tout un chacun a déjà vécu [...] cette rencontre des cultures à l'intérieur de lui-même: nous sommes tous des croisés». Estos cruces, que se producen por diferentes razones, pueden encontrar un punto de conexión común con otros individuos y la lengua constituye uno de ellos. En el caso de estas autoras, el francés, lengua de aprendizaje y de estudios en los países de adopción, va a integrarlas en las nuevas culturas; este idioma va abrir sus mentes al conocimiento del mundo desde una perspectiva más compleja de lo habitual. Según Aleida Assmann (citada en Roos, 2013: 338):

[...] el idioma sirve como vehículo para transmitir los recuerdos no solamente de los padres a los hijos, sino que incluye también la generación de los abuelos en la dinámica de la memoria comunicativa. Se trata entonces de una memoria de tres generaciones (antiguamente incluía hasta cinco) que opera en un marco temporal de entre ochenta y cien años, dado que es el periodo en el que diferentes generaciones existen simultáneamente, formando, a través del intercambio personal, una comunidad de experiencias, recuerdos y relatos.

La escritura concede a los autores exiliados la facultad de salir del aislamiento al permitirles explicar su recorrido vital, el proceso de memoria que siguen trata de restablecer la biografía familiar. Las novelistas de este estudio confirman que no hablan solamente de sus vidas, sino que integran en sus relatos vivencias de otras personas que compartieron esas mismas vicisitudes, añadiendo así a la narración el componente sociológico.

Las dos autoras, Thúy y Alcoba, eligen el francés como lengua de expresión literaria y como elemento generador de comprensión de la propia identidad, convirtiendo así la lengua francesa en esqueleto que sustenta sus identidades. Comprobamos por las declaraciones de L. Alcoba cómo sus libros quedan en los límites de la literatura, pues no desea pronunciarse 
claramente por algo ya predeterminado por el canon; ella afirma que «desde el punto de vista del género siempre estoy cruzando fronteras [...] Me interesa estar en eso que implica estar en dos cosas al mismo tiempo [...] mover las fronteras siempre es interesante» (Menestrina, 2020: 75). Este traspaso de límites tiene que ver no solo con el género literario que utiliza, sino también con ese traslado del presente al pasado, de Francia a Argentina, en el caso de esta escritora, pero que puede extrapolarse a la situación de Kim Thúy. Por tanto, la nueva generación de escritoras viviendo una situación de exilio no cuenta el pasado desde un punto de vista nostálgico ni de privación, sino que lo integran y lo hacen convivir completando una misma y única identidad que no se entiende aisladamente, sino en íntima comunión.

\section{Experiencia del exilio en Laura Alcoba y Kim Thúy}

Laura Alcoba deja su Argentina natal en 1979 para reencontrase con su madre exiliada en París, ya que su padre estaba encarcelado por pertenecer a la organización guerrillera Montoneros en la década de 1970. Durante un tiempo, la relación entre padre e hija será solamente epistolar y, posteriormente, se reunirá tras su liberación con ellas en Francia. Kim Thúy debe huir de Vietnam hacia Malasia donde permanece varios meses en un campo de refugiados en condiciones míseras antes de instalarse en el Canadá francófono, en la región de Quebec. Su acogida en este país es tan gratificante que afirma no haberse sentido nunca tan bella como el reflejo que percibió en la mirada de la persona que la recogió a su llegada; Kim describe sus sentimientos por su acogida en tierra canadiense con estas palabras en una entrevista concedida en 2018 al periódico Lemétropolitain: «Je me suis revue dans leur regard. Je n'ai jamais été aussi belle qu'à ce moment-là et je ne suis jamais redevenue aussi belle qu'à ce moment-là» ${ }^{3}$. Las dos autoras parten de historias colectivas específicas que imprimen a su exilio tonalidades y limites variables, aunque la lengua para narrarlos sea la misma en ambas: el francés.

Las narraciones sobre el exilio solapan diferentes formas, pero la diversidad formal no puede esconder lo que todas tienen en común: «un retour sur soi et une réflexion identitaire» (Riendeau, 2010: 137). A través de las obras de Alcoba y Thúy trataremos de comprender las razones y las consecuencias de la elección de una lengua en la actividad de la escritura para las escritoras que viven en el exilio, pero que, a pesar de ello, se sienten integradas en la sociedad de acogida. Las dos escritoras deciden relatar ese pasado, que creían asimilado tras la vuelta al país natal, siendo ya adultas y con carreras profesionales afianzadas. Sin embargo, el retorno a los lugares de la infancia y la historia pasada supone el comienzo de su vocación literaria.

\subsection{El exilio en la obra de Laura Alcoba}

Laura Alcoba vivió el terror de la dictadura argentina siendo niña. Pífano y Paz-Mackay, (2016: 131) enmarcan sus obras dentro de las consideradas como de segunda generación, aquella que no pretende ya dar a conocer 
los hechos, puesto que se da por sentado que el lector ya tiene conocimiento de las actuaciones del régimen dictatorial. Los escritores de esta segunda generación desean reflexionar sobre los hechos y sus consecuencias; varias publicaciones de esta escritora evocan las vivencias infantiles en el país de origen y otras fases posteriores ya en el exilio.

La primera publicación de esta autora, Manèges. Petite histoire argentine, relata su infancia durante los años setenta en la ciudad de La Plata; en particular, tras la muerte del general Perón en 1974, momento en el que el grupo guerrillero Montoneros pasa a la clandestinidad bajo el mandato de Isabel de Perón y de López Rega, organizador el grupo parapolicial de la triple A. La historia abarca hasta la dictadura militar de Videla y la salida de Laura Alcoba para el exilio en 1978. En aquellos momentos de clandestinidad, la niña tiene 8 años y vive con su madre escondida en la casa que da título al libro, en la que se imprime el periódico de la resistencia: Evita Montonera. El padre, a quien Laura visita en prisión acompañada de sus abuelos, permanecía encarcelado como opositor al régimen. Su madre cambió su identidad y la de su hija durante el periodo de residencia en aquella 'casa de los conejos'4 en la que se encargaba de la impresión de la publicación junto con otros integrantes del comando con los que la niña entablará una relación muy cercana.

\footnotetext{
Nous nous rendons, ma mère et moi, dans une nouvelle maison où nous faisons la connaissance d'un jeune couple : ils s'appellent Daniel et Diana, mais o on les appelle souvent Cacho et Didi.

Diana est enceinte, mais ça ne se voit presque pas [...] Je sens immédiatement que son sourire me fait beaucoup de bien. [...] mais je vois bien que ce sourire appartient à un temps passé, à quelque chose que je sais à tout temps perdu (Alcoba, 2007: 43).
}

Estas personas, Daniel y Diana, serán asesinadas poco después de la huida de Laura y su madre al exilio, tras la delación de uno de los integrantes de aquel comando. Este primer libro de Alcoba se abre con una pregunta realizada a Diana: «Tu dois te demander pourquoi j'ai tant tardé à raconter cette histoire?» (Alcoba, 2007: 13). «Elle porte sans doute un autre nom, elle ignore probablement qui furent ses parents et comment ils sont morts. Mais je suis sûre, Diana, qu'elle a ton sourire lumineux» (Alcoba, 2007: 139).

A lo largo de su relato, comprendemos que el silencio sobre aquellos acontecimientos se había impuesto como necesidad de supervivencia en su familia; silencio que se instala primeramente en La Plata para no ser detectados por los servicios secretos de la triple A y, más tarde en el país de asilo, para olvidar e integrarse en la nueva realidad. No desea que queden trazas de su pasado en su nueva lengua ni en su entorno, tratando de alejarse de cualquier marca que descubra su condición de exiliada, así como del sufrimiento vivido.

Laura averiguará los acontecimientos ocurridos en aquella casa tiempo después: la escritora conocerá los datos a través del libro Los del 73: memoria Montonera que le entrega su progenitor. Ella recuerda: «ll n'a rien dit d'autre. C'est que nous avons vraiment beaucoup de mal à parler de tout ça» (Alcoba, 2007: 134); dificultad para hablar de los hechos entre los 
implicados, pero que encuentra en la escritura literaria y en la lengua francesa el modo de expresión apropiado. Aquellos acontecimientos, escritos en su lengua materna, se trasladarán en sus novelas al francés como si esta lengua extranjera le ayudara a distanciarse de los acontecimientos, consiguiendo con ello un esclarecimiento del pasado más cerebral y menos emotivo. Esta segunda lengua se convierte a la vez en idioma primero para su vida cotidiana en el país galo y será la lengua de sus estudios, que le hacen evolucionar íntima e intelectualmente. Laura Alcoba no rechaza su lengua materna, puesto que escribe artículos en esa lengua y el español forma parte esencial de su tarea como profesora de literatura especialista en el Siglo de Oro español; sin embargo, ha elegido la lengua francesa para su obra literaria, rechazando hacer las traducciones al español de sus libros.

Tras algunas publicaciones menos relacionadas con su historia íntima, aunque sí conectadas con el mundo hispano-argentino, la escritora publica Le bleu des abeilles en 2013. Esta novela continua el relato de su historia personal, instalada ya en Francia, en la zona de Blanc-Mesnil, localidad cercana a París. La capital francesa había sido imaginada en los meses de espera para el exilio, a través del aprendizaje del francés con su profesora en La Plata. Ya entonces descubre las particularidades del acento grave 0 circunflejo $o$ de la $c$, aspectos de la lengua por los que demuestra una inclinación particular, pero permanece en un estadio de admiración estética de los rasgos fónicos o gráficos del francés. La niña establece contacto con la familia y las amistades que permanecen en Argentina por medio de las cartas que les escribe regularmente y que le permiten crearse una realidad paralela: «C'est qui est bien, avec les lettres, c'est qu'on peut tourner les choses comme on veut sans mentir pour autant” (Alcoba, 2013: 19). El intercambio de acontecimientos, opiniones y sentimientos, a través de las misivas entre padre e hija, le descubren el poder de las palabras para poder revelar su verdad de aquel escenario.

La historia de este libro nos adentra en la integración paulatina de la niña en el barrio y en la escuela. Simultáneamente, en la evolución hacia la adolescencia, la narradora comprende las limitaciones impuestas por la censura de la cárcel, que le hacen tomar conciencia de la importancia de cómo se cuentan las cosas. El padre guiará sus lecturas siguiendo su labor formativa con la que su hija se compromete, la literatura le facilita las claves que conformarán la identidad de la narradora. En particular, y relacionado con el título Le bleu des abeilles, la niña debe leer la obra de Maurice Maeterlinck, La vie des abeilles, cuya lectura supondrá un reto personal difícil. Esta decisión se convierte en un desafío frente al «otro», el nativo, encarnado en su caso por la bibliotecaria que no la cree capaz de entender la complejidad del texto. El conocimiento de la lengua francesa le permite comprender textos cada vez más complejos, el título del libro de Alcoba cita a las abejas y las une al color azul que nombra al comienzo del libro en la cita de Clarice Lispector (Alcoba, 2013: 9): «Le bleu est-il une couleur en soi, ou une question de distance?». La cita corrobora, en nuestra opinión, esa distancia que le ofrece el idioma que le abrió la puerta a la comprensión de lo que había vivido y a la posibilidad de renacer en el nuevo país, con nuevos amigos y una nueva lengua. 
En los comienzos de su aprendizaje del francés, la niña descubre en la lengua rasgos de sensualidad: «j'ai découvert des sons nouveaux un $r$ très humides que l'on va chercher au fond tout au fond de la gorge, et des voyelles qu'on laisse raisonner sous le nez, comme si on voulait à la fois les prononcer et les garder un peu pour soi» (Alcoba, $2013: 12$ ). Se deja atraer por la musicalidad de los sonidos, incluso sin prestar atención a la significación (Alcoba, 2013: 55):

Je peux rester longtemps, comme ça, à me laisser bercer pour la musicalité de la langue française - je lâche prise du côté des paroles pour ne m'intéresser qu'à la mélodie, au mouvement des lèvres de tous ces gens qui arrivent à cacher des voyelles sous leur nez, sans effort, sans y penser.

Pero en el fondo de este interés radica un deseo de integración, de no ser detectada por su acento extranjero para sentirse una más, tratando de dejar atrás los momentos del pasado llenos de pánico, para olvidar el miedo ante la sospecha de algún compañero de su madre cuando le cuestionaba si sería capaz de esconder su verdadero nombre o de no confesar el lugar en el que vivía con otros guerrilleros en la «casa de los conejos».

La adolescente está encantada de asistir a un colegio donde entabla amistad con compañeras que hablan «un français de source» (Alcoba, 2013: 58). La atracción por el idioma va más allá de la mera capacidad comunicativa; ella quiere dejar fluir la lengua aprendida por su mera belleza y por la posibilidad de expresar sus emociones, miedos o alegría sin ninguna censura frente a tantos silencios del pasado e, incluso, de la necesidad de aislarse de la lengua española en la que debe escribir a su padre porque estaba prohibido recibir cartas en otra lengua que no fuera el español, ni siquiera una cita de los libros que, sin embargo, ella leía en francés.

Será también por la lengua francesa que la pequeña argentina —no tiene nombre en el libro- se sentirá una más en su proceso de integración en su adolescencia. Su amiga, Nadine, tiene dificultades con la articulación de ciertos fonemas en su lengua materna lo que le hace sentirse cómplice de ella frente a las burlas de los compañeros; problemas de dicción que Alcoba (2013:109-110) detalla así:

\footnotetext{
Nadine zézaye, elle glisse des $z$ partout, elle douche toutes les voyelles de sa salive [...] Je n'aime pas du tout qu'on se moque d'elle et Nadine le sait, dès que quelqu'un l'imite, je rougis autant qu'elle [...] Pourtant, je sais que, au fond, ça me fait un peu plaisir qu'elle parle aussi bizarrement, qu'elle ait ce défaut de prononciation que tout le monde entend. Ces voyelles qu'elle noie dans sa propre écume et qui font pouffer les autres me rendent très triste et me réjouissent au même temps, c'est bizarre : c'est pour tout ça que je l'aime bien, Nadine.
}

Comparte con su amiga, por quien siente una gran admiración y estima, la huella de marginalidad, y así la integra como un proceso más de la existencia, deslindado de su condición de exiliada.

La trilogía familiar de la huida hacia la tierra de asilo se cierra con su última publicación La danse de l'araignée (2017), en la que se reencuentra con los tres miembros de la familia en París; situación inusitada que la narradora cuenta así (Alcoba, 2017: 142): «C'est étrange de voir mon père après tout 
ce temps. [...] J'ai l'impression de le voir pour la première fois». La escritura paterna le era más familiar que su cara, tras varios años casi sin verse en persona; la literatura francesa se había convertido para la narradora en el territorio de intercambio entre ellos dos ${ }^{5}$. La profundización en la lengua francesa hace del diccionario un personaje, Robertito, convirtiéndose en elemento indispensable en su vida «comme une vraie personne, au fond» (Alcoba 2017: 131). Según Staes (2020: 38), a pesar de la distancia de su país natal todo lo que vivió allí fue interiorizado y la marcó de forma traumática, por lo que no puede acercarse a aquellos hechos si no es escribiendo directamente en otra lengua, negándose a ser su propia traductora y, al inscribirse en el sistema literario francés, la autora adopta una postura monolingüe.

\subsection{El exilio en la obra de Kim Thúy}

Los textos de Kim Thúy revelan una satisfacción personal por habitar en un país como Canadá; desde su llegada a esa tierra las manifestaciones de su acogida son favorables, como muestra la narradora de $R u$ (2010: 35): «Pendant toute une année, Granby a représenté le paradis terrestre». La realidad de un país como Canadá cuya esencia es la suma de culturas, quizás diste mucho de otros países asentados como tales desde hace siglos. Robert Dion (1997: 187) afirma que la literatura quebequesa está constituida por un pensamiento desterritorializado y deshistorializado propicio a todas las hibridaciones. Névine El Nossey y Anna Rocca (2011: 3-5) ratifican que la característica más importante de la escritura migratoria es el desplazamiento del espacio nacional al espacio del yo y sus relaciones con el mundo. Estos escritos tienen la capacidad de descubrir, a través de la decodificación de la disparidad que existe en nosotros, nuestras similitudes con el otro; es decir, encontramos nuestras propias características en aquel que, a primera vista, es diferente a nosotros. En los distintos libros publicados, la escritora relata su aventura personal y familiar desde su infancia en Vietnam a la instalación en Canadá, dejando constancia de que no desea permanecer aislada por el pasado ni por nada que suponga una separación impuesta. Rememorando el muro que se construyó en su propia casa en Saigón que separaba las dependencias de los soldados instalados en la casa familiar de sus habitaciones, ella afirma que: «Beaucoup de choses ont changé depuis que ce mur de brique a été érigé entre nous et les communistes. [...] il n'y aura jamais de murs de brique dans ma maison» (Thúy, 2010: 42).

Kim Thúy nació en 1968 durante la ofensiva del Têt, como la voz de la narradora de $R u$ (2009) confirma: «J'ai vu le jour à Saigon, là où les débris des pétards éclatés en mille miettes coloraient le sol de rouge comme [...] le sang de deux millions de soldats déployés dans les villes et les villages d'un Vietnam déchiré en deux» (Thúy, 2010: 11). A pesar de la guerra, pasó su infancia con cierta tranquilidad, pero la familia se vio obligada a abandonar Vietnam a la llegada de la dictadura comunista. Huyeron en unas barcazas en condiciones infrahumanas e inseguras, por lo que algunas naufragaron. Tras una estancia en un campo de refugiados en Malasia, Ilegaron a Quebec, donde sus vidas cambiaron radicalmente. El padre de Kim Thuy, filósofo de formación, tuvo que repartir pizzas o trabajar 
como cajero de una tienda para sobrevivir en Canadá. Su madre, nieta de un prefecto de policía en Vietnam, se vio obligada a trabajar como limpiadora o costurera, tarea en la que era ayudada por sus hijos. En otra de sus novelas, Vi (2016), la narradora vuelve también atrás en el tiempo para contar parte de su historia familiar sobre su abuelo paterno, licenciado en Derecho en la universidad de Hanoi. Este dato le sirve para marcar las diferencias sociales en la época colonial francesa en Indochina entre los indígenas y los franceses. La formación y exigencia eran iguales, pero los títulos no eran equiparables: "La France s'occupait de l'instrution de ses sujets, mais n'attribuait pas la même valeur aux diplômes décernés dans ses colonies» (Thúy, 2016: 9). Los acontecimientos de la época colonial francesa casi no se evocan en su primera novela, $R u$, en la que se centra en la inserción de su familia en la sociedad de acogida en paralelo a algún recuerdo de Vietnam. La experiencia del exilio que pone de relieve Kim Thúy presenta una forma de enfrentarse a él como una posibilidad de renacer, tratando de alejarse del rencor: "C'est grâce à ce recul que j'ai réussi à partager des repas avec ceux qui furent le bras droit et le bras gauche de Ho Chí Minh sans voir la rancune planer» (Thúy, 2010: 44). La vuelta al país natal veinte años después —vivió allí tres años por su trabajo como abogada - le exige colaborar con aquellos por los que se vieron obligados a huir, pero no tiene una visión nostálgica de pérdida.

Para esta escritora, el exilio supone un enriquecimiento personal no una desventaja; comparte con Laura Alcoba la visión de la hibridación según los criterios que F. Aubes (2010: 25) denomina «la experiencia de la complementariedad cultural», rasgos que aparecen en otros autores de l'entre-deux. Kim Thúy es consciente de que ya se ha convertido en 'otra' para sus ex-compatriotas; además, sentada en un restaurante en Saigon, el camarero que le sirve le hace tomar consciencia de esa diferencia con las mujeres del país oriental: «[il] m'a rappelé [...] que je n'avais plus le droit de me proclamer vietnamienne parce que j'avais perdu leur fragilité, leur incertitude, leurs peurs. Et il avait raison de me reprendre» (Thúy, 2010: 8687). El modelo femenino de mujer que presenta la narradora no guarda ya la fragilidad física ni psíquica de la mujer vietnamita. La memoria constituye un elemento esencial en sus textos; el objetivo de la rememoración traslada esos acontecimientos más banales, que no aparecen en los libros de historia, a las generaciones futuras: «Je raconte ces anecdotes à Pascal pour garder en mémoire un pan de l'histoire qui ne retrouvera jamais sa place dans les bancs de l'école» (Thúy, 2010: 46); pero esos sucesos de aparente superficialidad archivan un punto de vista más íntimo de igual forma significativo para el individuo.

La narración de $R u$ encuentra el equilibrio entre la fuerza de los temas elegidos, que presenta, mediante escenas fragmentadas que se conectan implícitamente, y el tono ligero que aplica en su relato, recurriendo al humor o a anécdotas personales. Para hablar de sus dificultades escolares en su país de asilo, la protagonista recuerda qu' «il y avait un écart flagrant entre mes notes scolaires et les résultats de mes tests de quotient intellectuel, qui frisaient la déficience» (2010: 82). La escritora consigue, a través de la superposición de cuadros de su vida, ofrecer una visión mitigada de las dificultades que ha de afrontar no solo como individuo en exilio, sino también como madre de un hijo autista. La narración se encuentra dividida 
en capítulo muy cortos no marcados como tales y, en ocasiones, de solo media página. Estos se encuentran seguidos por espacios en blanco como esfera de sugestión para lo que en ocasiones es «indecible», siguiendo estilísticamente a otra escritora de Indochina: Marguerite Duras. Todo ello hace que la percepción de los hechos violentos se solape con otros que ofrecen el lado más dulce de la existencia. Consiguiendo así que la percepción del lector no ignore los hechos acaecidos, pero que se interpreten desde una perspectiva optimista.

El tono de la escritura de $R u$ está ya en la significación del título; por un lado, en vietnamita designa una canción de cuna y, por otro, significa arroyo en francés. Partiendo de la infancia alegre y protegida en su país natal, la narración se adentra en el fluir de la vida de la protagonista, ligada al devenir familiar. Según Ching Selao (2014: 150) «Kim Thúy semble [...] avoir ce que j'appellerai un parti pris pour le bonheur». La fragmentación narrativa responde a esa composición/descomposición de su personalidad entre dos países, dos continentes, dos visiones del mundo y dos tradiciones ancestrales que encuentra siempre un lazo de unión vivencial y estilístico.

Hay aspectos de su vida que, sin embargo, ha perdido para siempre y que quedan patentes por meras anécdotas que permiten, sin embargo, conocer la problemática del abandono de la cultura de origen. Por ejemplo, una costumbre habitual para todo vietnamita es el desayuno a base de sopas de sémola o de arroz acompañado de carne o pescado; la protagonista de $R u$, al ser preguntada por su maestra de Granvy sobre qué desayunaba y oír su respuesta, corroborada por otros alumnos vietnamitas, no salía de su asombro, lo que motivó una llamada telefónica a las familias, que abandonaron esa costumbre. La narradora a partir de entonces no suele desayunar (Thúy, 2010: 112); este dato intrascendente, pero que constituye una rutina del ser humano, da una medida de las trasformaciones a las que se exponen los exiliados que deben recomenzar su vida en otro lugar obligados por las circunstancias en su mayoría políticas o económicas.

\section{Conclusión}

Nuestro estudio pretendía analizar la obra de dos escritoras del siglo XXI que parten al exilio, se instalan en países de asilo y publican sus novelas ya en la edad madura, tras desarrollar otras profesiones. La literatura constituye para ellas el espacio de la reflexión sobre su identidad, pero sobre todo se constituye en la plataforma en la que integrar una experiencia del exilio con la que pueden identificarse muchos seres anónimos que lo han soportado en silencio. Las novelas de Laura Alcoba y de Kim Thúy nos ofrecen la oportunidad de conocer historias minúsculas, que la Historia olvida. En este siglo en el que estamos confrontados casi a diario con la problemática del exilio y la migración, en la que mueren en el intento muchos de estos seres humanos, la literatura adquiere una dimensión más sociológica y da vida al anonimato de muchos de ellos cuyos rasgos estas escritoras amalgaman para crear sus personajes.

Sus obras ponen de relieve que existen otros territorios diferentes de «la madre patria» en los que las personas desarrollan una vida plena, ese 
espacio de la lengua en la que se vehiculan las experiencias; en ese caso, la lengua francesa les ha permitido desarrollar su obra que se ha convertido en el caso de Kim Thúy en su única profesión. El traslado de las vivencias traumáticas del exilio puede exigir otra lengua que permita crear una distancia para comprender la realidad y para trasladar un mensaje de optimismo, pero sobre todo para construirse una identidad nueva que se fundamenta en las antiguas experiencias de la infancia.

\section{Bibliografía citada}

ALCOBA, L. (2007): Manège. Petite histoire argentine, París: Gallimard (col. Folio).

ALCOBA, L. (2013): Le bleu des abeilles, París: Gallimard.

ALCOBA, L. (2017): La danse de l'araignée, París: Gallimard.

ALCOBA, L. (2017): «Laura Alcoba présente son dernier ouvrage "La danse de l'araignée"», La grande librairie $<$ https://www.youtube.com/watch?v=rSADIRh9CQo > [22/06/2021]

AUBĖS, Françoise (2010): «Si loin, si près : diaspora et globalisation chez les écrivains transnationaux», América: Cahier du CRICCAL, 39, 23-29.

BIANCHI, O. (2005): «Penser l'exil pour penser l'être», Le Portique, $<$ http://journals.openedition.org/leportique/519>, [25/03/2021]

DESPLECHIN, F. (2015): «L'identité dans l'exil: entre crainte de l'oubli et fantasme inconscient de trahison. Le travail clinique auprès de demandeurs d'asile», L'Information psychiatrique-1, vol. 91, pp. 45-52.

DION, R. (1997): Le moment critique de la fiction. Les interprétations de la littérature que proposent les fictions québécoises contemporaines, Quebec: Nota Bene.

EL NOSSEY, N. y Anna ROCCA (2011): «Introduction» en El Nossey, N. y A. Rocca (eds.), Frictions et devenir dans les écritures migrantes au féminin, Berlín: Éditions Universitaires Européennes.

GEFEN, A. (2016): "Le projet thérapeutique de la littérature contemporaine française", Contemporary french and francophone studies, vol. 20-3, 420-427.

GIRARD, J.-Y (2015): "Le sens de la vie selon Kim Thúy» en Girard J.Y., Ducharme A. y M. Labrèche-Larouche, À propos de la vie-Le sens de la vie selon 20 personnalités. Montreal: Éditions La Presse, 211-217.

LEVY-BERTHERAT, D. (2017): «La petite fille épique chez Léonora Miano, Kim Thúy et Laura Alcoba», Revue critique de fixxion françaises contemporaine, 1323.

$<$ http://www.revue-critique-de-fixxion-francaisecontemporaine.org/rcffc/article/view/fx14.03/1102> [12/04/2021]

MENESTRINA, E. M. (2020): «La experiencia del exilio determina y deja huella para siempre: entrevista a la escritora Laura Alcoba», Anclajes, vol. 24-2, 63-78.

MATA BARREIRO, C. (2004): «Identité urbaine, identité migrante », Recherches sociographiques, 45, 1, 39-52.

MATA-BARREIRO, C (2020): "L'écriture migrante francophone comme objet de recherche» en Cremades Cano, I.D. y A. Pagan López (eds.) Voix francophones de la migration, Toulouse: Les Presses universitaires. Institut Catholique de Toulouse, 17-36.

MALAVOY, T. (2016): «Kim Thúy : deux classes de migrants ? », L'Actualité, $<$ https://lactualite.com/culture/kim-thuy-deux-classes-de-migrants/>, [19/05/2021] NOUSS, A. (2015): La condition de l'exilé. Penser les migrations contemporaines, París: Maison des Sciences de l'Homme.

PÉNICAUD, M. (2015): «Alexis Nouss, "La condition de l'exilé. Penser les migrations 
[19/05/2021].

PÉREZ-BRIGNOLI, H. (2017): «Aculturación, transculturación, mestizaje: metáforas y espejos en la historiografía latinoamericana», en Cuadernos de Literatura, vol. XXI, 41, 96-113.

PÍFANO, D. y PAZ-MACKAY, S. (2016): «La casa de los conejos de Laura Alcoba y la (re)construcción de la identidad en el marco del doloroso legado del terrorismo de Estado en Argentina», Poligramas, 42, 127-146.

QUANG PHAM, V. (2020): "L'idée de l'exile chez Pham van Ky et Linda Lê», International Journal of Francophone Studies, vol. 23, 1-2, 143-154.

REY DE CASTRO, V. (2017): "Narrar desde la niña que fui. Configurar subjetividades en "La casa de los conejos" y "El azul de las abejas" de Laura Alcoba», Inti: Revista de literatura hispánica, 85, 215-235.

RIENDEAU, P. (2010): «Chacun en son exil», Voix et Images, Vol 36-1, 106, 137 142.

RIVIÈRES, P. (2010): «Le fabuleux destin de Kim Yhúy ou le regard du rêve», Forum, <htpp://www.nouvelles.umontreal.ca/campus/activites-speciales-etinvite/20100315-le-fabuleux-destin-de-kim-thúy-ou-le-regard-du-r-ve.html>, [02/05/2017]

ROOS, S. (2013): «Micro y macrohistoria en los relatos de filiación chilenos», Aisthesis, 54, 335-351.

SAID, E. W. (2001): Fuera de lugar, Barcelona: Grijalbo (Mondadori).

SELAO. Ch. (2014): «Oiseaux migrateurs. L'expérience exilique chez Kim Thúy et Linda Lê», Voix et Images, vol. 40, 1, 149-164.

STAES, S. (2020): «¿Traducción como superación? Trauma y (re)escritura en Le bleu des abeilles de Laura Alcoba», Iberoamericana XX, 75, 37-50.

TODOROV, T. (1996): L'homme dépaysé, París: Seuil.

THUMEREL, F. (2004): Annie Ernaux, une œuvre de l'entre-deux, Arras: PU Artois.

THÚY, K (2010): Ru, París: Éditions Liana Lévi.

THÚY, K (2016): Vi, París: Éditions Liana Lévi.

VIART, D. (2009): "Le silence des pères au principe du "récit de filiation"», en Études françaises, 96-112.

VIART, D. (2019): «El relato de filiación. Ética de la restitución contra deber de memoria en la literatura contemporánea», Cuadernos LIRICO, 20, $<$ http://journals.openedition.org/lirico/8883>, [17/04/2021]

\footnotetext{
1 Diccionario Real Academia de la Lengua Española, URL $<$ https://dle.rae.es/transculturaci\%C3\%B3n\#alqYBxO> [29/11/2021]

2 Site de la Bibliothèque des Amériques, "Cinq questions à Kim Thúy " $<$ https://www.bibliothequedesameriques.com/actualites-litteraires/portraits-dauteurs/6questions-kim-thuy $>$, [29/11/2021]

${ }^{3} \mathrm{Kim}$ Thúy https://lemetropolitain.com/kim-thuy-une-amoureuse-de-la-langue-francaise/

4 Título de la traducción en español.

5 Entrevista en el programa de France 5 La grande librairie minuto 4'45. < https://www.france.tv/france-5/la-grande-librairie/81031-james-ellroy-andrei-kourkov-kim$\underline{\text { thuy.html> Video que no está disponible en la actualidad en España. }}$
} 